\title{
Intensity of care and withdrawal of life-sustaining therapies in severe traumatic brain injury patients: a post-hoc analysis of a multicentre retrospective cohort study
}

\section{Intensité de soins et retrait de maintien des fonctions vitales chez des patients ayant subi un traumatisme craniocérébral grave : une analyse post-hoc d'une étude de cohorte multicentrique rétrospective}

Peter R. A. Gerges, MD, MSc $\cdot$ Lynne Moore, PhD $\cdot$ Caroline Léger, PhD $\cdot$ François Lauzier, MD, MSc $\cdot$ Michèle Shemilt, MSc $\cdot$ Ryan Zarychanski, MD, MSc $\cdot$ Damon C. Scales, MD, PhD $\cdot$ Karen E. A. Burns, MD, MSc $\cdot$ Francis Bernard, MD $\cdot$ David Zygun, MD $\cdot$ Xavier Neveu, MSc $\cdot$ Alexis F. Turgeon, MD, MSc on behalf of Canadian Critical Care Trials Group

Received: 23 December 2017/Revised: 20 March 2018/Accepted: 25 April 2018/Published online: 14 June 2018

(C) Canadian Anesthesiologists' Society 2018

\begin{abstract}
Purpose The intensity of care provided to critically ill patients has been shown to be associated with mortality. In patients with traumatic brain injury (TBI), specialized neurocritical care is often required, but whether it affects clinically significant outcomes is unknown. We aimed to determine the association of the intensity of care on mortality and the incidence of withdrawal of life-sustaining therapies in critically ill patients with severe TBI.
\end{abstract}

Electronic supplementary material The online version of this article (https://doi.org/10.1007/s12630-018-1171-6) contains supplementary material, which is available to authorized users.

This manuscript is accompanied by an editorial. Please see Can J Anesth 2018; 65: this issue.

P. R. A. Gerges, MD, MSc · L. Moore, PhD - C. Léger, PhD · F. Lauzier, MD, MSc $\cdot$ M. Shemilt, MSc $\cdot$ X. Neveu, MSc A. F. Turgeon, MD, MSc $(\bowtie)$

CHU de Québec - Université Laval Research Center, Population Health and Optimal Health Practices Research Unit, Trauma Emergency - Critical Care Medicine, Université Laval, 1401, 18e rue, local Z-204, Québec City, QC G1J 1Z4, Canada e-mail: alexis.turgeon@fmed.ulaval.ca

\section{Moore, $\mathrm{PhD}$}

Department of Social and Preventive Medicine, Université Laval, Québec City, QC, Canada

F. Lauzier, MD, MSc · A. F. Turgeon, MD, MSc Division of Critical Care Medicine, Department of Anesthesiology and Critical Care Medicine, Université Laval, Québec City, QC, Canada
Methods We conducted a post hoc analysis of a multicentre retrospective cohort study of critically ill adult patients with severe TBI. We defined the intensity of care as a daily cumulative sum of interventions during the intensive care unit stay. Our outcome measures were all-cause hospital mortality and the incidence of withdrawal of life-sustaining therapies.

Results Seven hundred sixteen severe TBI patients were included in our study. Most were male (77\%) with a mean (standard deviation) age of 42 (20.5) yr and a median [interquartile range] Glasgow Coma Scale score of 3 [3-6]. Our results showed an association between the intensity of care and mortality (hazard ratio [HR], 0.69; 95\% confidence

F. Lauzier, MD, MSc

Department of Medicine, Université Laval, Québec City, QC, Canada

R. Zarychanski, MD, MSc

Department of Internal Medicine, Sections of Critical Care Medicine, Haematology and of Medical Oncology, University of Manitoba, Winnipeg, MB, Canada

D. C. Scales, MD, PhD - K. E. A. Burns, MD, MSc

Interdepartmental Division of Critical Care Medicine, University of Toronto, Toronto, ON, Canada

D. C. Scales, MD, PhD

Sunnybrook Research Institute, Sunnybrook Health Sciences

Centre, Toronto, ON, Canada 
interval [CI], 0.63 to 0.74) and the incidence of withdrawal of life-sustaining therapy (HR, 0.73; 95\% CI, 0.67 to 0.79).

Conclusion In general, more intense care was associated with fewer deaths and a lower incidence of withdrawal of lifesustaining therapies in critically ill patients with severe TBI.

\section{Résumé}

Objectif L'intensité des soins fournis à des patients dans un état critique est associée à la mortalité. Chez des patients ayant subi un traumatisme craniocérébral (TCC), des soins intensifs neurologiques spécialisés sont souvent nécessaires, mais on ignore s'ils ont un impact cliniquement significatif sur le devenir de ces patients. Nous avons cherché à déterminer l'association entre, d'une part, l'intensité des soins et, d'autre part, la mortalité et l'incidence du retrait des thérapies de maintien des fonctions vitales chez des patients dans un état critique suivant un TCC.

Méthodes Nous avons réalisé une analyse post hoc d'une étude de cohorte multicentrique rétrospective chez des patients dans un état critique suivant un TCC grave. Nous avons défini l'intensité des soins par la somme cumulée journalière des interventions au cours du séjour en unité de soins intensifs. Nos intensifs d'évaluation étaient la mortalité hospitalière, toutes causes confondues, et l'incidence du retrait des thérapies de maintien des fonctions vitales.

Résultats Sept cent seize patients atteints de TCC grave ont été inclus dans notre étude. La plupart étaient des hommes (77\%) d'un âge moyen (écart-type) de $42(20,5)$ ans et ayant un score de Glasgow pour le coma (Glasgow coma scale) médian [écarts interquartiles] de 3 [3 à 6]. Nos résultats ont montré une association entre l'intensité des soins et la mortalité (rapport de risque [RR] : 0,69; intervalle de confiance [IC] à $95 \%: 0,63$ à $0,74)$ et l'incidence du retrait des thérapies de maintien des fonctions vitales (RR: 0,73; IC à $95 \%$ : 0,67 à 0,79).

Conclusion D’une manière générale, des soins plus intenses ont été associés à moins de décès et à une plus faible incidence du retrait des thérapies de maintien des fonctions vitales chez des patients dans un état critique suivant un TCC grave.

K. E. A. Burns, MD, MSc

Li Ka Shing Knowledge Institute, St-Michaels Hospital,

Toronto, ON, Canada

F. Bernard, MD

Department of Internal Medicine, Université de Montréal,

Montréal, QC, Canada

D. Zygun, MD

Department of Critical Care Medicine, University of Alberta,

Edmonton, AB, Canada
Traumatic brain injury (TBI) is a major global health problem. An average of 1.4 million cases of TBI occur every year in the United States with 50,000 associated deaths. ${ }^{1}$ In Canada, serious brain injuries occur to 165,000 persons each year. ${ }^{2}$ The care provided to patients with TBI can be defined in terms of quality as well as quantity, also known as intensity of care. The incidence of mortality and unfavorable outcomes associated with severe TBIs remains high $^{3}$ with limited improvement in recent decades ${ }^{4-11}$ despite concurrent improvements in quality of care in the intensive care unit (ICU). This raises a question regarding the potential of other aspects of care, such as intensity, to affect clinical outcomes.

Intensity of care has been shown to be associated with lower mortality in the general ICU population and specifically in non-surgical and neurocritically ill populations. ${ }^{12,13}$ Very few studies to date have quantified intensity of care for patients with severe TBI. ${ }^{14}$ Nevertheless, a systematic review recently suggested that trauma centres providing aggressive treatment and monitoring of severe TBI patients had improved neurologic outcomes and reduced mortality. ${ }^{15} \mathrm{~A}$ cohort study showed that mortality and decisions to withdraw lifesustaining therapies in patients with severe traumatic brain injury varied significantly across Canadian trauma centres. ${ }^{16}$ These findings may suggest a potential association between intensity of care and decisions to withdraw life-sustaining therapies in patients with severe TBI.

We aimed to evaluate the association of the intensity of care with the withdrawal of life-sustaining therapies and mortality in critically ill patients with severe TBI. Our hypothesis was that intensity of care was associated with decreased incidence of withdrawal of life-sustaining therapies and mortality.

\section{Methods}

We conducted a post hoc analysis of a large multicentre retrospective cohort study of critically ill patients with severe TBI. ${ }^{16,17}$ The multicentre cohort study was conducted in six level I trauma centres from three Canadian provinces (Québec, Ontario, Alberta) over a 24-month period $(n=720)(16,17)$. Patients were identified at all centres using the International Statistical Classification of Diseases and Related Health Problems, tenth revision (codes for traumatic brain injury: S06.0S06.9). We included 720 patients who were 1 ) $\geq 16$ yr old, 2) mechanically ventilated for $\geq 48 \mathrm{hr}$, and 3) admitted to an ICU following a blunt severe TBI with a Glasgow Coma Scale (GCS) score $\leq 8$. We randomly selected 120 patients 
Table 1 Components of intensity of care and interventions

\begin{tabular}{llll}
\hline Interventions & Medical & Surgical & Diagnostic \\
\hline Specific to TBI & $\bullet$ Mannitol & $\bullet$ ICP monitoring & $\bullet$ Head CT scan \\
& $\bullet$ Hypertonic saline & $\bullet$ Craniotomy/craniectomy & $\bullet$ Brain magnetic resonance imaging \\
& $\bullet$ Induced hypothermia & & $\bullet$ SSEP \\
& $\bullet$ Phenytoin & & \\
& $\bullet$ Barbiturates & & \\
Non-specific to TBI & $\bullet$ SjO2 monitoring & $\bullet$ Other surgical procedures & \\
& $\bullet$ Mechanical ventilation & \\
& $\bullet$ Vasopressors & \\
& $\bullet$ Propofol & \\
& $\bullet$ Intravenous insulin infusion & \\
& $\bullet$ Heparin \\
& $\bullet$ Opioids & \\
& $\bullet$ Benzodiazepines & \\
\hline
\end{tabular}

$\mathrm{CT}=$ computed tomography; $\mathrm{ICP}=$ intracranial pressure monitoring; $\mathrm{PEG}=$ percutaneous endoscopic gastrostomy; $\mathrm{SjO}_{2}=$ jugular venous saturation; SSEP = somatosensory evoked potentials; TBI = traumatic brain injury

from the trauma registries and/or discharge databases at each centre. We excluded patients with penetrating brain injuries and those with no record of ICU stay. Trained research assistants reviewed the charts and retrieved data at each centre using a standardized case report form. Research Ethics Board approval was obtained from all participating institutions.

\section{Intensity of care}

We defined intensity of care based on the number and type of interventions performed during the ICU stay. We divided these interventions into two main categories: 1) specific to TBI and 2) interventions not specific to TBI. Additionally, we classified each of these interventions into three mutually exclusive categories: 1) medical, 2) surgical, and 3) diagnostic interventions (Table 1). Interventions were measured for a maximum of 14 days following admission to the ICU or for fewer days if the patient died or was discharged from the ICU before day 14 . The intensity of care referred to a score that is the cumulative sum of interventions performed on each day during the ICU stay for each patient. This daily "intensity" may range from 0 to a maximum of 22 .

\section{Outcome measures}

Our outcome measures were all-cause hospital mortality and withdrawal of life-sustaining therapies. Withdrawal of life-sustaining therapy was coded when therapies such as mechanical ventilation, inotropes, vasopressors, or renal replacement therapy were withdrawn without the expectation of survival.

\section{Data collection}

At each centre, qualified and trained research personnel with nursing or medical backgrounds retrieved the data. We extracted the following patient characteristics at the time of admission: age, sex, GCS motor score, pupillary reactivity, cause of trauma, injury severity score, and other associated traumatic injuries (Table 2) as well as the types of interventions used throughout the ICU stay (Table 3).

\section{Statistical analysis}

We evaluated the association of the intensity of care with mortality and the withdrawal of life-sustaining therapies using a Cox shared frailty model ${ }^{18,19}$ to take account of between-cluster heterogeneity. We used the extended Cox model to allow the number of interventions (and other covariables) to vary over time. We used counting process methodology based on Anderson-Gill data structure. ${ }^{20-22}$ Allowing the number of interventions to vary over time allowed us to avoid survivor treatment bias and violations in proportional-hazards assumptions. ${ }^{23}$

Intensity of care was operationalized by creating a composite measure aggregating the contributing interventions (Table 1) over the first 14 days in the ICU. The use of each contributing intervention was assessed on a daily basis ( 1 point if present; maximum 22 points per day for total intensity). Models were adjusted for sex and three 
Table 2 Patient characteristics

\begin{tabular}{|c|c|c|c|c|c|}
\hline \multirow[b]{2}{*}{$\begin{array}{l}\text { Characteristics } \\
n(\%)\end{array}$} & \multicolumn{3}{|l|}{ Overall } & \multicolumn{2}{|c|}{ Non-survivors } \\
\hline & $\begin{array}{l}\text { Total } \\
(n=716)\end{array}$ & $\begin{array}{l}\text { Survivors } \\
(n=488)\end{array}$ & $\begin{array}{l}\text { Non-survivors } \\
(n=228)\end{array}$ & $\begin{array}{l}\text { WLST } \\
(n=160)\end{array}$ & $\begin{array}{l}\text { No WLST } \\
(n=68)\end{array}$ \\
\hline \multicolumn{6}{|l|}{ Demographics } \\
\hline Age (mean [SD]) & $42(20)$ & $39(19)$ & $51(22)$ & $54(21)$ & $43(21)$ \\
\hline Age $>55$ yr & $213(29)$ & $102(21)$ & $111(48)$ & $88(55)$ & $23(34)$ \\
\hline Male sex & $551(77)$ & $391(80)$ & $160(70)$ & $110(69)$ & $50(74)$ \\
\hline \multicolumn{6}{|l|}{ Cause of trauma } \\
\hline Motor vehicle collision & $399(56)$ & $292(60)$ & $107(47)$ & $67(42)$ & $40(59)$ \\
\hline Assault (stuck by/against) & $54(7)$ & $42(8)$ & $12(5)$ & $5(3)$ & $7(10)$ \\
\hline Fall & $214(30)$ & $120(25)$ & $94(41)$ & $74(46)$ & $20(29)$ \\
\hline Other & $31(4)$ & $20(4)$ & $11(5)$ & $10(6)$ & $1(2)$ \\
\hline Unknown & $18(3)$ & $14(3)$ & $4(2)$ & $4(3)$ & $0(0)$ \\
\hline Non-reactive pupils & $155(22)$ & $25(5)$ & $130(57)$ & $84(53)$ & $46(68)$ \\
\hline Injury severity score (median [IQR]) & $30[25-41]$ & $29[25-41]$ & $34[25-43]$ & $29[25-41]$ & $36[26-45]$ \\
\hline \multicolumn{6}{|l|}{ Abbreviated injury scale head } \\
\hline Missing or 9 & $288(40)$ & $172(35)$ & $116(51)$ & $89(56)$ & $27(40)$ \\
\hline 1 or 2 & $16(2)$ & $14(3)$ & $2(1)$ & $1(1)$ & $1(2)$ \\
\hline 3 & $26(4)$ & $22(5)$ & $4(2)$ & $4(2)$ & $0(0)$ \\
\hline 4 & $113(16)$ & $99(20)$ & $14(6)$ & $7(4)$ & $7(10)$ \\
\hline 5 or 6 & $273(38)$ & $181(37)$ & $92(40)$ & $59(37)$ & $33(48)$ \\
\hline GCS total score (median [IQR]) & $3[3-6]$ & $6[3-7]$ & $3[3-4]$ & 3 [3-4] & $3[3-3]$ \\
\hline \multicolumn{6}{|l|}{ GCS motor score } \\
\hline 1 & $352(49)$ & $187(38)$ & $165(72)$ & $107(67)$ & $58(85)$ \\
\hline 2 or 3 & $67(9)$ & $42(9)$ & $25(11)$ & $21(13)$ & $4(6)$ \\
\hline 4,5 , or 6 & $285(40)$ & $250(51)$ & $35(16)$ & $29(18)$ & $6(9)$ \\
\hline Unknown & $12(2)$ & $9(2)$ & $3(1)$ & $3(2)$ & $0(0)$ \\
\hline Median [IQR] & $2[1-4]$ & $4[1-5]$ & $1[1-2]$ & $1[1-3]$ & $1[1-1]$ \\
\hline
\end{tabular}

$\mathrm{IQR}$ = interquartile range; GCS = Glasgow Coma Scale; SD = standard deviation; WLST = withdrawal of life-sustaining therapy

baseline confounding factors, which are known to be associated with prognosis of severe traumatic brain injury: age (dichotomized at $55 \mathrm{yr}$ ), ${ }^{24-28}$ absence of pupillary reactivity, ${ }^{8,29-32}$ and motor score on the GCS on ICU admission. ${ }^{8,30-34}$ Motor GCS score ${ }^{35,36}$ was categorized as follows: $1,2-3,4-6 .{ }^{17,37}$

We reported associations with hazard ratios (HR) and corresponding $95 \%$ confidence intervals (CI). The HR was interpreted as an average effect of the time-varying factor "intensity of care" over the period of observation.

We conducted sensitivity analyses to assess whether results vary according to ICU length of stay (three day, seven day, discharge) or type of intervention. Analyses were conducted using SAS version 9.4 software (SAS Institute, Cary, NC, USA).

Sample size

We randomly selected 120 patients (60 patients per year) from the trauma registries and/or discharge databases of each of the six centres using the International Statistical Classification of Diseases and Related Health Problems, tenth revision (codes for traumatic brain injury: S06.0 S06.9). This sample size was calculated to generate $95 \%$ confidence intervals (CI) with $\pm 10 \%$ precision for proportion of death associated with withdrawal of lifesustaining therapy.

\section{Results}

We excluded four patients because of missing ICU discharge time. A total of 716 severe TBI patients were included in our analyses. Most patients were male $(77 \%)$ with a mean [standard deviation (SD)] age of 42.4 (20.5) yr and a median (interquartile range [IQR]) GCS score of [36] on admission (Table 2). Hospital mortality was $32 \%(n$ $=228$ ) with most deaths $(70 \%)$ associated with decisions to withdraw life-sustaining therapies. Interventions by 
Table 3 Interventions used to determine the intensity of care

\begin{tabular}{|c|c|c|c|c|c|}
\hline \multirow[b]{2}{*}{ Interventions } & \multicolumn{3}{|l|}{ Overall } & \multicolumn{2}{|c|}{ Non-survivors } \\
\hline & $\begin{array}{l}\text { Total } \\
(n=716)\end{array}$ & $\begin{array}{l}\text { Survivors } \\
(n=488)\end{array}$ & $\begin{array}{l}\text { Non-survivors } \\
(n=228)\end{array}$ & $\begin{array}{l}\text { WLST } \\
(n=160)\end{array}$ & $\begin{array}{l}\text { No WLST } \\
(n=68)\end{array}$ \\
\hline \multicolumn{6}{|l|}{ Medical } \\
\hline Mechanical ventilation & $710(99)$ & $482(99)$ & $228(100)$ & $160(100)$ & $68(100)$ \\
\hline $\mathrm{SjO}_{2}$ monitoring & $29(4)$ & $20(4)$ & $9(4)$ & $5(3)$ & $4(6)$ \\
\hline Vasopressor infusion & $268(38)$ & $126(26)$ & $142(62)$ & $91(57)$ & $51(75)$ \\
\hline Propofol & $485(68)$ & $373(76)$ & $112(49)$ & $82(51)$ & $30(44)$ \\
\hline Barbiturates & $10(1)$ & $3(1)$ & $7(3)$ & $5(3)$ & $2(3)$ \\
\hline Opioids & $409(57)$ & $304(62)$ & $105(46)$ & $81(51)$ & $24(35)$ \\
\hline Benzodiazepine & $363(51)$ & $289(59)$ & $74(33)$ & $56(35)$ & $18(27)$ \\
\hline Mannitol & $216(30)$ & $113(23)$ & $103(45)$ & $76(48)$ & $27(40)$ \\
\hline Hypertonic saline & $112(16)$ & $64(13)$ & $48(21)$ & $33(21)$ & $15(22)$ \\
\hline Muscle-paralyzing agents & $86(12)$ & $54(11)$ & $32(14)$ & $19(12)$ & $13(19)$ \\
\hline Phenytoin & $420(59)$ & $303(62)$ & $117(51)$ & $88(55)$ & $29(43)$ \\
\hline Insulin intravenous infusion & $412(58)$ & $266(55)$ & $146(64)$ & $113(71)$ & $33(49)$ \\
\hline DVT prophylaxis & $249(35)$ & $224(46)$ & $25(11)$ & $17(11)$ & $8(12)$ \\
\hline Induced hypothermia & $69(10)$ & $36(7)$ & $33(15)$ & $24(15)$ & $9(13)$ \\
\hline \multicolumn{6}{|l|}{ Surgical } \\
\hline Intracranial pressure monitoring & $214(30)$ & $135(28)$ & $79(35)$ & $58(36)$ & $21(31)$ \\
\hline Craniotomy/craniectomy & $166(23)$ & $108(22)$ & $58(25)$ & $44(28)$ & $14(21)$ \\
\hline Tracheotomy/tracheostomy OR PEG tube insertion & $158(22)$ & $150(31)$ & $8(4)$ & $6(4)$ & $2(3)$ \\
\hline Other surgical procedures & $247(35)$ & $205(42)$ & $42(18)$ & $26(16)$ & $16(24)$ \\
\hline Surgical procedure within the first $48 \mathrm{hr}$ & $328(46)$ & $225(46)$ & $103(45)$ & $75(47)$ & $28(41)$ \\
\hline \multicolumn{6}{|l|}{ Diagnostic } \\
\hline Head CT scan & $538(75)$ & $425(87)$ & $113(47)$ & $84(53)$ & $29(43)$ \\
\hline Brain magnetic resonance imaging & $93(13)$ & $78(16)$ & $15(7)$ & $12(8)$ & $3(4)$ \\
\hline Electroencephalogram & $86(12.0)$ & $65(13.3)$ & $21(9.2)$ & $16(10.0)$ & $5(7.4)$ \\
\hline Somatosensory evoked potentials & $15(2.1)$ & $8(1.6)$ & $7(3.1)$ & $5(3.1)$ & $2(2.9)$ \\
\hline
\end{tabular}

Numbers in parentheses are percentages

$\mathrm{CT}=$ computed tomography; DVT = deep venous thrombosis; GCS = Glasgow Coma Scale; OR = operating room; PEG = percutaneous endoscopic gastrostomy; $\mathrm{SjO}_{2}=$ central jugular venous saturation monitoring; WLST $=$ withdrawal of life-sustaining therapy

mortality and withdrawal of life-sustaining therapies are presented in Table 3.

\section{Adjusted mortality}

In the overall analysis, an HR of 0.69 (95\% CI, 0.63 to $0.74)$ suggested that the hazard of mortality decreased by an average of $31 \%$ for each additional intervention, if all other covariates were held fixed. In the same manner, an association with decreased mortality was observed with TBI-related interventions (HR, $0.71 ; 95 \% \mathrm{CI}, 0.60$ to 0.85 ) and interventions not specifically related to TBI (HR, 0.67; $95 \% \mathrm{CI}, 0.60$ to 0.75$)$. When analyzed by type of intervention, medical interventions (HR, 0.69; 95\% CI, 0.63 to 0.76 ) and diagnostic testing ( $\mathrm{HR}, 0.57 ; 95 \% \mathrm{CI}$, 0.40 to 0.83 ) were significantly associated with a reduction of mortality hazards, whereas the association was not statistically significant with surgical interventions (HR, 0.76; 95\% CI, 0.57 to 1.01) (Table 4). Similar associations were observed regardless of the timing of outcome assessment (eTable 1, available as Electronic Supplementary Material [ESM]).

Withdrawal of life-sustaining therapies

Adjusted Cox proportional hazard analyses showed a significant decrease in the hazards of withdrawing lifesustaining therapies in the overall cohort with increasing overall intensity of care (HR, $0.73 ; 95 \% \mathrm{CI}, 0.67$ to 0.79 ). This reduction in the hazard of withdrawing life-sustaining therapies was observed for both the intensity of traumatic brain injury-related interventions ( $\mathrm{HR}, 0.75$; $95 \% \mathrm{CI}, 0.62$ to 0.92 ) and interventions not specifically related to TBI (HR $0.71 ; 95 \%$ CI, 0.63 to 0.81 ). When analyzed by type of 
Table 4 Adjusted hazard ratios of the intensity of care on mortality

\begin{tabular}{llll}
\hline Intensity of Care & HR* & \multicolumn{2}{l}{$95 \% \mathrm{CI}$} \\
\cline { 3 - 4 } Overall & 0.69 & 0.64 & 0.74 \\
\hline Type of Intervention & & & \\
TBI-specific & 0.71 & 0.60 & 0.85 \\
Non TBI-specific & 0.67 & 0.60 & 0.75 \\
Medical & 0.69 & 0.63 & 0.76 \\
Surgical & 0.76 & 0.57 & 1.01 \\
Diagnostic & 0.57 & 0.40 & 0.83 \\
\end{tabular}

*Adjusted for sex, age, pupillary reactivity, and score on the Glasgow Coma motor scale. The HR is interpreted as an average effect of the time-varying factor "intensity of care" over the period of observation; $\mathrm{CI}=$ confidence interval of hazard ratio $\mathrm{HR}=$ hazard ratio; $\mathrm{TBI}=$ traumatic brain injury

Table 5 Adjusted hazard ratios of the intensity of care on the incidence of withdrawal of life-sustaining therapies

\begin{tabular}{llll}
\hline Intensity of Care & $\begin{array}{l}\text { HR* } \\
\text { Overall }\end{array}$ & $05 \% \mathrm{CI}$ & \\
\cline { 4 - 4 } Type of Intervention & 0.73 & 0.67 & 0.79 \\
TBI-specific & 0.75 & 0.62 & 0.92 \\
Non TBI-specific & 0.71 & 0.63 & 0.81 \\
Medical & 0.74 & 0.67 & 0.82 \\
Surgical & 0.73 & 0.50 & 1.06 \\
Diagnostic & 0.58 & 0.37 & 0.90 \\
\hline
\end{tabular}

*Adjusted for sex, age, pupillary reactivity and score on the Glasgow Coma motor scale. The HR was interpreted as an average effect of the time-varying factor "intensity of care" over the period of observation; $\mathrm{CI}=$ confidence interval of hazard ratio $\mathrm{HR}=$ hazard ratio; $\mathrm{TBI}=$ traumatic brain injury

intervention, intensity of medical interventions (HR 0.74; 95\% CI, 0.67 to 0.82 ) and diagnostic testing (HR 0.58; $95 \% \mathrm{CI}, 0.37$ to 0.90 ) were significantly associated with a reduced hazard of withdrawal of life-sustaining therapies, whereas the association was not significant with surgical interventions (HR 0.73; 95\% CI, 0.50 to 1.06) (Table 5 and subgroup analysis in eTable 2 [available as ESM]). When looking at withdrawal of life-sustaining therapies in nonsurvivors only, similar findings were observed, as well as for the sensitivity and subgroup analyses (eTable 3 and eTable 4; available as ESM).

\section{Discussion}

In our study, we observed that increasing intensity of care provided to severe TBI patients is associated with lower mortality and lower incidence of withdrawal of lifesustaining therapies, even after adjusting for severity of illness, age, and pupillary reactivity. These associations were observed even if intensity of care was assessed based on TBI-related interventions or interventions not specifically related to traumatic brain injury, and specifically for medical interventions and diagnostic testing. In sensitivity analyses, the association of intensity of care with outcome was maintained throughout the ICU stay, regardless of the timing of assessment.

\section{Context with previous literature}

No previous study has specifically addressed the impact of intensity of care in the TBI population across centres at a patient level. One previously published study evaluated the effect of intensity of care on mortality following severe TBI. The results of this study suggested that a decreased intensity of care in the elderly patients was a possible cause for the increased mortality observed in this population. ${ }^{38} \mathrm{In}$ our study, we controlled and adjusted for age and observed that this inverse relationship between intensity of care and mortality was not restricted to the elderly but present in the whole population. A systematic review with meta-analyses of cohort studies examined the effect of aggressive monitoring (mainly intracranial pressure monitoring) on mortality in patients with severe TBI. ${ }^{14}$ Centres considered to be using aggressive monitoring had lower mortality. This finding has been observed in a previous study. ${ }^{15}$ In our study, all centres were using intracranial pressure monitoring as part of the standard of care, which enabled us to address the question at a patient level by adjusting for a potential centre effect using hierarchical modelling. ${ }^{18}$ Our study was also designed to quantify intensity of care as a continuous, time-varying variable. Interestingly, we did not observe an association between surgical intensity, including intracranial pressure monitoring, and mortality or the incidence of life-sustaining therapies.

\section{Strengths and limitations}

One important limitation of our study is the absence of long-term functional outcome measures, which are considered standard of care to evaluate patients with traumatic brain injury. Nonetheless, the evaluation of the short-term association of intensity of care with mortality and the incidence of withdrawal of life-sustaining therapies is clinically relevant considering that these events occur early in the care of patients with severe traumatic brain injury. Second, we used data from a previous study that was not designed to evaluate the impact of intensity of care on outcome measures and in which data collection regarding intensity of care was limited to the first 14 days in the ICU. This may be an adequate data collection period, since the most active phase of care is in the first week after injury and most deaths and decisions to 
withdraw life-sustaining therapies occur within this twoweek period. ${ }^{16}$ Third, we quantified intensity of care by assigning an equal weight to the different interventions. We aimed to evaluate the relative association of these interventions, defined by the overall cumulative sum of the intensity of care in patients with severe TBI, with mortality and the incidence of withdrawal of life-sustaining therapies. Notwithstanding, some interventions may play a greater role in the observed associations than others, as addressed in part by our subgroup analyses for type of intervention. Fourth, the most important limitation of our study is likely the fact that we only adjusted for four confounders. Nevertheless, the strength of the confounders we adjusted for with our outcome is the most important among all potential known confounders. Nonetheless, the probability of residual confounding is quite high, and this may explain, in part, the associations observed between intensity of care and mortality and the incidence of withdrawal of life-sustaining therapies. Despite having adjusted for the most important prognostic indicators, we cannot exclude the possibility of bias by indication. Indeed, the clinician's decision to use more aggressive care may be related to unmeasured risk factors. A Pygmalion effect (self-fulfilling prophecy) may thus explain our findings, physicians being more aggressive with patients they believe have a chance to survive or have a more favorable prognosis. Contrarily, since most deaths are associated with a decision to withdraw life-sustaining therapies in this population and physicians are involved in this shared-decision making process, a lower intensity of care may be provided to the patients and explain the findings.

Our study has several strengths. First, our study used data collected from six trauma centres across Canada offering a broad representation of potential current practice variation. Second, we used hierarchical modelling to partition variance between centres and patients. Third, we modelled intensity of care as a time-varying variable and stratified by window of exposure. Failure to appropriately account for changes in treatment intensity over time could lead to survivor treatment bias and overestimates of potential benefits of interventions. Finally, we also took into consideration the incidence of withdrawal of lifesustaining therapies in our analysis, as many deaths in severe TBI patients are associated with these decisions. ${ }^{16}$

\section{Conclusion}

We observed a significant association between the overall intensity of care and the incidence of both mortality and withdrawal of life-sustaining therapies in critically ill patients with severe TBI. Nevertheless, we cannot exclude the possibility of important residual confounding, such as a bias by indication, considering that patients with a less favorable prognosis may not benefit from the same interventions during the acute phase of care (selffulfilling prophecy). Future research should aim to understand how clinicians make decisions regarding intensity of care for patients with severe TBI and clarify the impact of decision-making on outcomes and resource allocation.

Acknowledgements The authors thank Frédéric Morin, David Simonyan, Mohana Ratnapalan, Stephanie Todd, and John Harlock for their help in data acquisition. The authors are grateful to the Grants and Manuscripts review committee of the Canadian Critical Care Trials Group, and more specifically to Dr. Lauralyn McIntyre, for the review and critical appraisal of the manuscript.

Disclaimer The views expressed in the submitted article are the authors' views and are not an official position of the institutions or funders.

Conflicts of interest None declared.

Editorial responsibility This submission was handled by Dr. Philip M. Jones, Associate Editor, Canadian Journal of Anesthesia.

Author contributions Peter R. A. Gerges, Lynne Moore, François Lauzier, Ryan Zarychanski, and Alexis F. Turgeon were involved in conception and design. Peter R. A. Gerges, Lynne Moore, Xavier Neveu, Michèle Shemilt, and Alexis F. Turgeon were involved in the acquisition and statistical analysis. Peter R. A. Gerges, Caroline Léger, Michèle Shemilt, and Alexis F. Turgeon drafted the manuscript. All authors were involved in the interpretation of the data, revising the manuscript, and approval of the final version.

Funding This work was supported in part by the Foundation of the Centre hospitalier affilié universitaire de Québec (CHA). Drs. Moore and Lauzier are recipients of a research career award from the Fonds de la Recherche du Québec - Santé (FRQS). Dr. Zarychanski was a recipient of a CIHR New Investigator award. Dr. Turgeon is the Canada Research Chair in Critical Care Neurology and Trauma.

\section{References}

1. Langlois JA, Rutland-Brown W, Wald MM. The epidemiology and impact of traumatic brain injury: a brief overview. J Head Trauma Rehabil 2006; 21: 375-8.

2. Brain Injury Canada. Brain injury can happen to anyone. Available from URL: https://www.braininjurycanada.ca/wpcontent/uploads/2014/07/Brain-Injury-Can-Happen-to-Anyone. pdf (accessed April 2018).

3. Rosenfeld JV, Maas AI, Bragge P, Morganti-Kossmann MC, Manley GT, Gruen RL. Early management of severe traumatic brain injury. Lancet 2012; 380: 1088-98.

4. Jennett B, Teasdale $G$, Galbraith $S$, et al. Severe head injuries in three countries. J Neurol Neurosurg Psychiatry 1977; 40: 291-8.

5. Foulkes MA, Eisenberg HM, Jane JA, Marmarou A. Marshall LF; Traumatic Coma Data Bank Research Group. The traumatic 
coma data bank: design, methods, and baseline characteristics. J Neurosurg 1991; 75: S8-13.

6. Murray LS, Teasdale GM, Murray GD, Miller DJ, Pickard JD, Shaw MD. Head injuries in four British neurosurgical centres. $\mathrm{Br}$ J Neurosurg 1999; 13: 564-9.

7. Murray GD, Teasdale GM, Braakman R, et al. The European Brain Injury Consortium survey of head injuries. Acta Neurochir (Wien) 1999; 141: 223-36.

8. Majdan M, Steyerberg EW, Nieboer D, Mauritz, W, Rusnak M, Lingsma $H F$. Glasgow coma scale motor score and pupillary reaction to predict six-month mortality in patients with traumatic brain injury: comparison of field and admission assessment. J Neurotrauma 2015; 32: 101-8.

9. Myburgh JA, Cooper DJ, Finfer SR, et al. Epidemiology and 12month outcomes from traumatic brain injury in Australia and New Zealand. J Trauma 2008; 64: 854-62.

10. $\mathrm{Ng}$ I, Lee $\mathrm{KK}$, Lim JH, Wong HB, Yan XY. Investigating gender differences in outcome following severe traumatic brain injury in a predominantly Asian population. Br J Neurosurg 2006; 20: 73-8.

11. Andriessen TM, Horn J, Franschman G, et al. Epidemiology, severity classification, and outcome of moderate and severe traumatic brain injury: a prospective multicenter study. J Neurotrauma 2011; 28: 2019-31.

12. Chen YC, Lin SF, Liu CJ, Jiang DD, Yang PC, Chang SC. Risk factors for ICU mortality in critically ill patients. J Formos Med Assoc 2001; 100: 656-61.

13. Kiphuth IC, Schellinger PD, Kohrmann M, et al. Predictors for good functional outcome after neurocritical care. Crit Care 2010; 14: R136.

14. Shore PM, Hand LL, Roy L, Trivedi P, Kochanek PM, Adelson $P D$. Reliability and validity of the Pediatric Intensity Level of Therapy (PILOT) scale: a measure of the use of intracranial pressure-directed therapies. Crit Care Med 2006; 34: 1981-7.

15. Stein SC, Georgoff P, Meghan S, Mirza KL, El Falaky OM. Relationship of aggressive monitoring and treatment to improved outcomes in severe traumatic brain injury. J Neurosurg 2010; 112: 1105-12.

16. Turgeon AF, Lauzier F, Simard JF, et al. Mortality associated with withdrawal of life-sustaining therapy for patients with severe traumatic brain injury: a Canadian multicentre cohort study. CMAJ 2011; 183: 1581-8.

17. Cote $N$, Turgeon AF, Lauzier F, et al. Factors associated with the withdrawal of life-sustaining therapies in patients with severe traumatic brain injury: a multicenter cohort study. Neurocrit Care 2013; 18: 154-60.

18. Carlin BP, Hodges JS. Hierarchical proportional hazards regression models for highly stratified data. Biometrics 1999; 55: $1162-70$.

19. Austin PC. A Tutorial on multilevel survival analysis: methods, models and applications. Int Stat Rev 2017; 85: 185-203.

20. Fine JP, Gray RJ. A proportional hazards model for the subdistribution of a competing risk. J Am Stat Assoc 1999; 94: 496-509.

21. Therneau TM. Extending the Cox Model. Rochester, Minnesota: Mayo Clinic. Biomedical Statistics and Informatics; 1996: report No. 58.
22. Austin PC, Mamdani MM, Van Walraven C, Tu JV. Quantifying the impact of survivor treatment bias in observational studies. J Eval Clin Pract 2006; 12: 601-12.

23. Kleinbaum DG, Klein M. Survival Analysis, A Self-Learning Text. 3rd ed. NY: Springer; 2012 .

24. Hukkelhoven $C W$, Steyerberg EW, Rampen AJ, et al. Patient age and outcome following severe traumatic brain injury: an analysis of 5600 patients. J Neurosurg 2003; 99: 666-73.

25. Demetriades D, Kuncir E, Velmahos GC, Rhee P, Alo K, Chan $L S$. Outcome and prognostic factors in head injuries with an admission Glasgow coma scale score of 3. Arch Surg 2004; 139: 1066-8.

26. Vollmer DG, Torner JC, Jane JA, et al. Age and outcome following traumatic coma: why do older patients fare worse? J Neurosurg 1991; 75: S37-49.

27. Signorini DF, Andrews PJ, Jones PA, Wardlaw JM, Miller JD. Predicting survival using simple clinical variables: a case study in traumatic brain injury. J Neurol Neurosurg Psychiatry 1999; 66: 20-5.

28. Nakamura $N$, Yamaura A, Shigemori $M$, et al. Final report of the Japan Neurotrauma Data Bank project 1998-2001: 1,002 cases of traumatic brain injury. Neurol Med Chir (Tokyo) 2006; 46: 56774.

29. Brain Trauma Foundation. American Association of Neurological Surgeons, Congress of Neurological Surgeons. Guidelines for the management of severe traumatic brain injury. $\mathrm{J}$ Neurotrauma 2007; 24(Suppl 1): S1-106.

30. Choi SC, Muizelaar JP, Barnes TY, Marmarou A, Brooks DM, Young $H F$. Prediction tree for severely head-injured patients. J Neurosurg 1991; 75: 251-5.

31. Hoffmann $M$, Lefering $R$, Rueger JM, et al. Pupil evaluation in addition to Glasgow coma scale components in prediction of traumatic brain injury and mortality. Br J Surg 2012; 99(Suppl 1): 122-30.

32. Marmarou A, Lu J, Butcher I, et al. Prognostic value of the Glasgow coma scale and pupil reactivity in traumatic brain injury assessed pre-hospital and on enrollment: an IMPACT analysis. J Neurotrauma 2007; 24: 270-80.

33. Hukkelhoven CW, Steyerberg EW, Habbema JD, et al. Predicting outcome after traumatic brain injury: development and validation of a prognostic score based on admission characteristics. J Neurotrauma 2005; 22: 1025-39.

34. Healey $C$, Osler TM, Rogers FB, et al. Improving the Glasgow coma scale score: motor score alone is a better predictor. J Trauma 2003; 54: 671-80.

35. Teasdale G, Jennett B. Assessment of coma and impaired consciousness. A practical scale. Lancet 1974; 2: 81-4.

36. Teasdale G, Jennett B. Assessment and prognosis of coma after head injury. Acta Neurochir (Wien) 1976; 34: 45-55.

37. Rivas JJ, Lobato RD, Sarabia R, Cordobes F, Cabrera A, Gomez $P$. Extradural hematoma: analysis of factors influencing the courses of 161 patients. Neurosurgery 1988; 23: 44-51.

38. Thompson HJ, Rivara FP, Jurkovich GJ, Wang J, Nathens AB, MacKenzie EJ. Evaluation of the effect of intensity of care on mortality after traumatic brain injury. Crit Care Med 2008; 36: 282-90. 